\title{
Cement bond evaluation using well logs: A case study in Raniganj Block Durgapur, West Bengal, India
}

\author{
Prashant Saini ${ }^{1} \cdot$ Harinandan Kumar ${ }^{1} \cdot$ Tarun Gaur $^{2}$
}

Received: 14 August 2020 / Accepted: 20 March 2021 / Published online: 29 March 2021

(c) The Author(s) 2021

\begin{abstract}
Cement bond $\log$ s (CBL) and variable density log (VDL) are one of the vital logging techniques used to evaluate cementcasing-formation bonds before the well testing or execution of the production operation in the well. These logs are also crucial during the workover operation to maintain the integrity of the well. The logging techniques provide a clear view of the quality of cement bonds with casing and formation. The microannulus and other deviations in bonding between the cement and the casing or formation are recorded using this technique. Therefore, this technique is used by the regulatory authorities worldwide for the determination of the cement bond with casing and formation. In this paper, the CBL/VDL logging technique was used to determine the bonding between cement and casing and cement and formation at two different CBM wells from 850 to 1600 m depths in the Raniganj block of Durgapur, West Bengal. Two well, namely, A and B, were analyzed to determine the cement-casing-formation bonds in the study area's coal seam zone. The analysis was carried out at normal and pressure pass to investigate the integrity of the well using the CBL/VDL data. The normal and pressure pass in well A indicated the presence of microannulus in the bonding between cement and casing/formation in the coal seam zone. The corresponding analysis of well B showed poor cement and formation bond at the coal seam zone during the normal pass but good bonding after the pressure pass. Thus, it was observed that the CBL/VDL data were capable of determining the cement-casing-formation bonds in both the well of the study area and the well's integrity.
\end{abstract}

Keywords Cementation · Microannulus $\cdot$ Cement bond log $(\mathrm{CBL}) \cdot$ Variable density log (VDL)

\section{Introduction}

Cement evaluation plays a vital role in determining the bond quality between casing-cement and cement-formation in a wellbore. Detailed cement evaluation is paramount in CBM wells. It affects the perforation placement due to unconsolidated formation, which may permit cross-flow of sand (Jie, et al. (2014)) or water into the reservoir; thus, causing a loss of zonal isolation. Therefore, good cementing is essential to maintain good integrity (Cai 2016). This is due to the relatively low pore pressure present in the coal. Moreover, the presence of an unconsolidated formation

Harinandan Kumar

harinandankumar88@gmail.com

1 Department of Petroleum and Earth Science, University of Petroleum and Energy Studies, Bidholi, Dehradun, Uttarakhand 248007, India

2 Essar Oil and Gas Exploration and Production Limited, Molandighi, Durgapur, West Bengal 713212, India affects the bonding between the cement-formation due to water presence, which loses its viscidity property of bonding with cement. Thus, analysis of the bond quality is an essential parameter in CBM well to predict good integrity. The evaluation of cement-formation bonds is also crucial before the well testing and execution of the production from the well. Out of various techniques, the wireline logging method is the primary method to visualize the quality of the cement-formation bonds. The wireline logging method like cement bond logs (CBL) and variable density logs (VDL) was used elsewhere to evaluate the quality of cement bond behind a cemented casing or liner before a well test or production operation is performed in the well (Kyi and Wang 2015). The wireline logging method was used to determine the isolation zone in drilling operations to avoid unwanted cross-flows from behind the casing during production operations (Thiercelin et al. 1998; Timonin et al. 2014). The CBL/ VDL (CBL-V) method was used to evaluate the cement bond behind the casing of thin sandstone beds $(<7 \mathrm{~m})$ separated by thin shale/clay beds ( 1 to $8 \mathrm{~m}$ ) in the Assam Oil fields

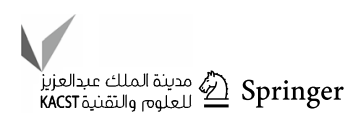


India. The results of the investigation helped to understand the nature of cement behind the casing and in deciding the feasibility, validity and necessity of a cement squeeze (Pal and Ahmed 2006). The combination of sonic and ultrasonic logging tools was used for the investigation of the cement sheath near the borehole for the assessment of $\mathrm{CO} 2$ injection. The presence of microannulus in the cement-casing bond was reported using the logging technique (Loizzoa et al. 2013). Waveforms of the pulse-echo method were used for the cement bonding evaluation. Bonding conditions of the cement-casing were determined in this study for the assessment of the extent of the microannulus in the bonds (Wang et al. 2016). From the literature survey, it is observed that the wireline logging method like CBL/VDL was used for the investigation of the well integrity before the production from the well. The normal pass, as well as pressure pass, were applied to evaluate the bonding. In the normal pass, no mechanical force was applied on the casing in the upward direction, while in the pressure pass, the mechanical force was applied on the casing.

In this investigation, the CBM well at Raniganj coalfield West Bengal India was considered to evaluate cement bond using Wireline logging like CBL/VDL method. Formations of the study area are homogeneous with varying permeability and reservoir pressure in the Raniganj block since low-density slurry is used because of the directional well and injection of low-density cement. Therefore, bonding problems are frequently encountered during well-cementing operations. The bonding problems are bonding the cement with the casing and formation and the quality of bond in different zones of the perforation. Poor bonds often cause a loss of circulation due to mechanical failure or a microannulus generation. A microannulus (a small gap between the casing and cement sheath) extends over long casing sections and fails to provide a hydraulic seal. Microannulus causes thermal expansion or contraction of the pipe during cementing. The presence of microannulus affects the well integrity and increases the higher risk of zonal isolation failure. Thus, it is essential to analyze the microannulus and cement bonding to improve the well's stability. Therefore, the Wireline logging like CBL/VDL method was used for the determination of the cement-casing as well as cement-formation bonds.

\section{Stratigraphy of Raniganj formation}

The Raniganj coalfields lie on the easternmost side of the Damodar Valley coalfields and cover an area of $3000 \mathrm{~km}^{2}$. The geological map and stratigraphy of the study area are shown in (Figs. 1 and 2). The formation mainly contains bituminous coal with well-preserved protogenesis pores and well-developed cracks and cleats. The Raniganj coalfield has seven main coal horizons in the Barakar coal measures and six in the Raniganj coal measures, and some thirty coal seams have been traced in Bokaro coalfields. The strata consist mainly of sandstones and shales, there being various types of gradation into one another, e.g., sandy shale, shaly sandstone, etc . (Table 1).

\section{Objectives}

The study's specific objective was to analyze and interpret the bonding between cement-casing and casing-formation using CBL-VDL logs and its effects on the well integrity.
Fig. 1 Geological Map of Raniganj coalfield (Essar Exploration and Production 2015)

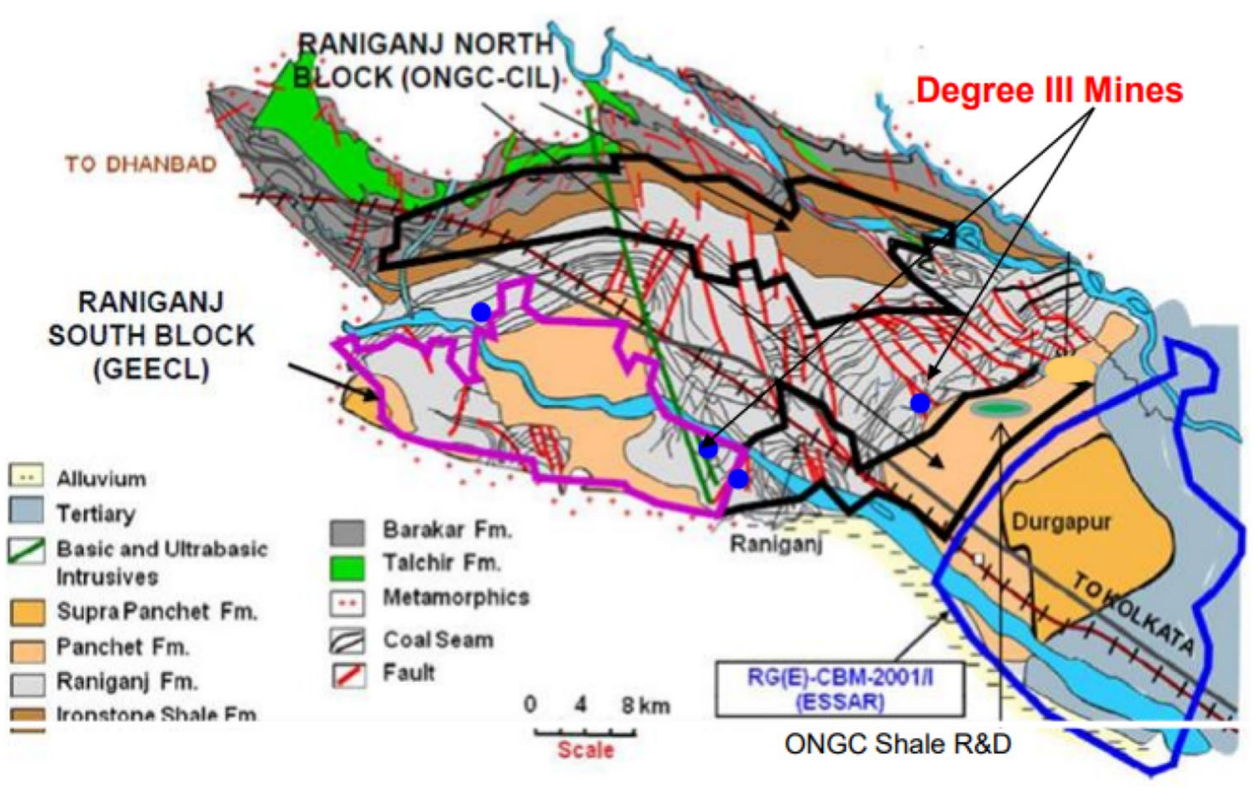




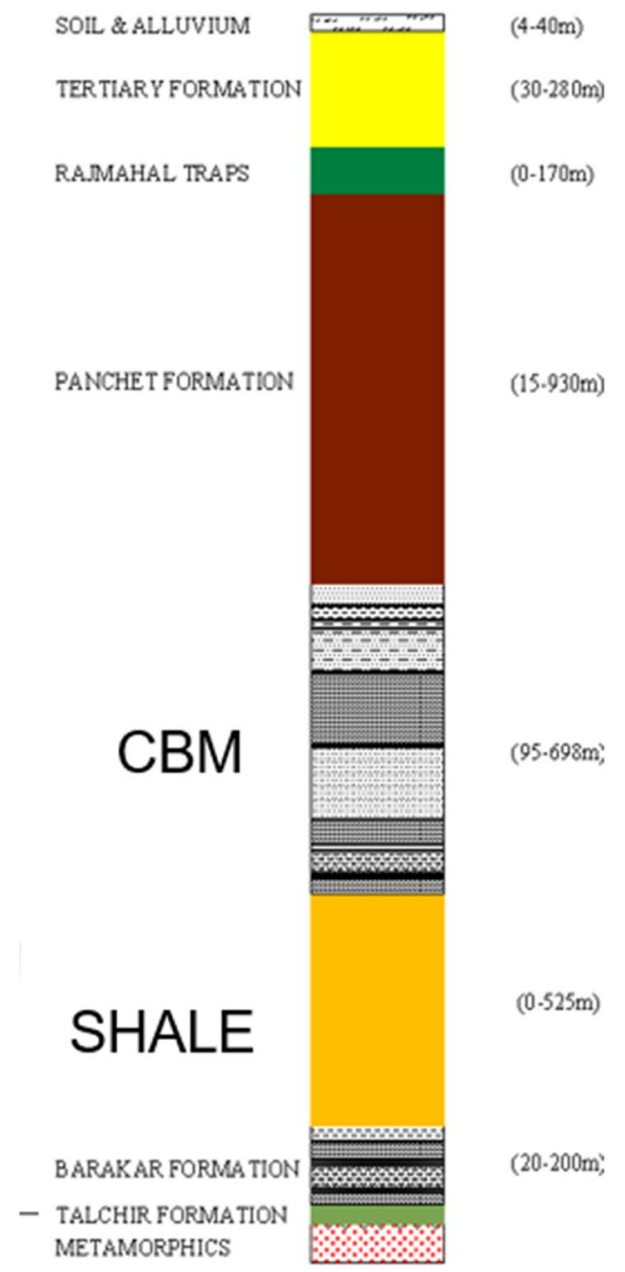

Fig. 2 Stratigraphy of Raniganj coalfield (Essar Exploration and Production 2015)

\section{Conventional cement bond logs}

The evaluation of cement quality with acoustic waves was introduced in the late 1950s when the first CBL, cement bond log, was run in the wellbore. The tool used for the investigation was a transmitter and two receivers spaced at
$3 \mathrm{ft}$ and $5 \mathrm{ft}$, respectively. These tools measured the amplitude of a sonic signal produced by a transmitter that emits acoustic waves with a frequency of around $20 \mathrm{kHz}$ after traveling through a short section in the casing as an extensional mode (Fig. 3). The measured amplitude was further converted into attenuation by using a ratio of multiple transmitters and receivers. CBL tool provides the required information of cement bond to the formation with a variable density log (VDL) waveform. The collected data were optimized by introducing the pressure pass technique.

\section{Procedure}

A sonic tool, as shown in Fig. 4, was used for the logging purpose. The cement bond log (CBL) was run in each well to evaluate the cement quality. A variable density log (VDL) was used to analyze the bonding between cement and formation. The cement bond logs were affected by the microannulus, and as a result, the cement quality assessment was hindered. The occurrence of the microannulus was observed during the placement of cement and pressurization of the casing. Thus, the pressure pass technique (pressure applied from the surface) was used to estimate the section of the casing affected by the microannulus. Cement evaluation results show that the cement bond logs are affected by the presence of the microannulus, and thus both tools can be successfully used to overcome the problems that occur in wells while performing the cement evaluation with the microannulus. The comparison of the CBL/VDL results before and after the pressure pass for different well-being zones was studied.

\section{Optimization of CBL-VDL data using pressure pass technique}

A pressure pass was used to check micro-channels behind the casing. In the pressure pass technique, the casing was pressurized by a known pressure (between 800 and 1000 psi) and maintained by a pressure unit. The data obtained were compared with the normal CBL-V data to determine
Table 1 Composition of strata in Raniganj coalfield (Chakrabortty et al. 2018)

\begin{tabular}{lll}
\hline Formation & Description & $\begin{array}{l}\text { Maximum } \\
\text { thickness } \\
(\mathrm{m})\end{array}$ \\
\hline Supra Panchet & Red and gray sandstone shales & 300 \\
Panchet & Micaceous yellow and gray sandstones, red and greenish shales & 600 \\
Raniganj & Gray and greenish soft telspathic sandstones, shales and coal seams & 1050 \\
Ironstone Shales & Dark carbonaceous shales with ironstone bands & 360 \\
$\begin{array}{l}\text { Barakar } \\
\text { Talcher with boul- } \\
\text { dered the base }\end{array}$ & Course and medium gray and white sandstones & 630 \\
\hline
\end{tabular}


a)

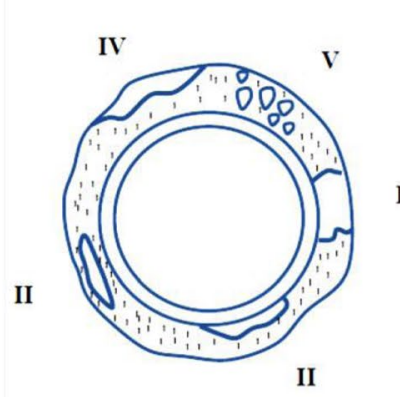

b)

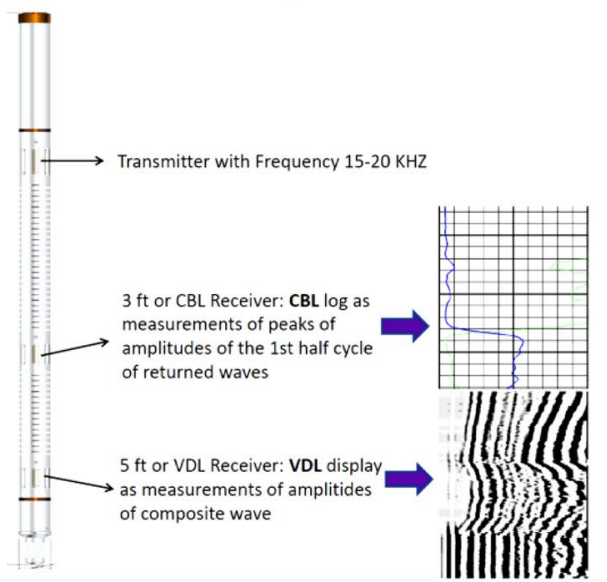

c)

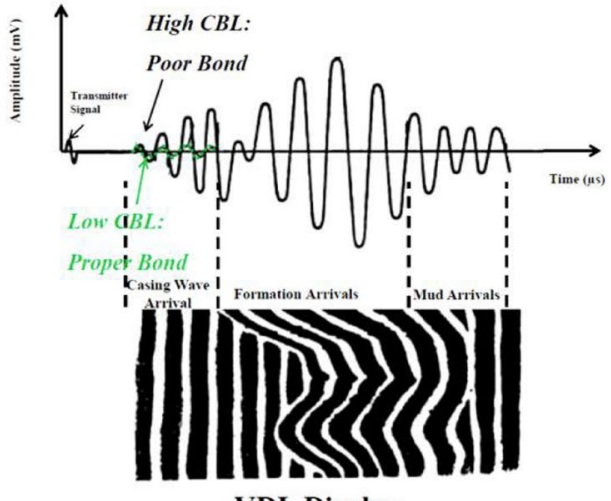

VDL Display

Fig. 3 a Different Channel Types in Cement Sheath, b Normal CBL-VDL Tool, c Poor and Good Cement Bond Detection (Ashena et al. 2014)

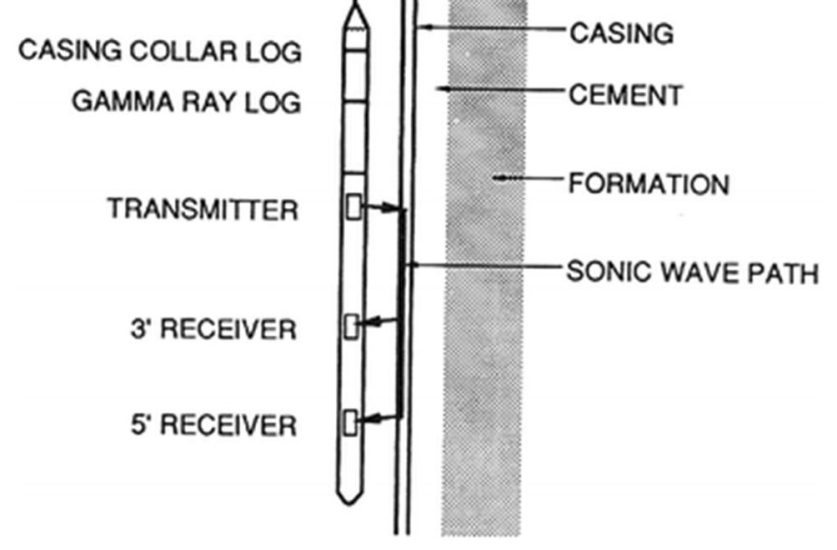

Fig. 4 Sonic Tool in the casing (Liu 2017)

the zones affected by the microannulus (Fig. 5). The wells were analyzed for good cementing and poor cementing using the CBL-V technique, and based on the above analysis, the zones with microannulus were identified.

\section{Results and discussion}

The results of the investigation are discussed in the following sub-sections as case studies.

\section{Case studies}

The results of two different wells are shown in case study I and case study II with the microannulus between the casings and cement sheath. A poor cement-formation bond was observed in well A at the coal zone, as discussed in case study I. The logging results of normal and pressure pass of Well B are discussed in case II. The detailed discussion is included in the following sub-sections. The results of normal and pressure pass in the coal seam zone indicated a good cement bond after perforation.

\section{Case study- I}

Well, A was drilled up to $1500 \mathrm{~m}$ as a directional well with a 5.5-inch casing. Cased hole logging was carried out to determine the bonding between casing-cement-formation. CBL-VDL log was obtained from the logging technique. In this logging, the coal seam zone was identified at a depth of $938 \mathrm{~m}$ from the surface (Fig. 6). Based on the CBL-VDL log data, the bonding was observed almost satisfactorily except for the coal seam, where a microannulus was observed, as shown in Fig. 6. The confirmation of microannulus presence was carried out using the pressure pass technique (Fig. 6). It was observed that the presence of microannulus in the casing inversely impacted the wellbore integrity and the rate of production of gas due to cross-flow of sand in the wellbore. The presence of this microannulus may increase the non-productive time. A higher rate of dewatering is also required for gas production due to the microannulus's presence. Thus, remedial measures were required to isolate the sand in order to overcome the situation of this microannulus. This remedial action application was essential to reduce the non-productive time (NPL) during the gas production operation.

\section{Case study- II}

Well B was drilled up to $1500 \mathrm{~m}$ as a directional well with a 5.5-inch casing. The CBL logging interval showed a poor bond quality between the casing-cement. The corresponding 


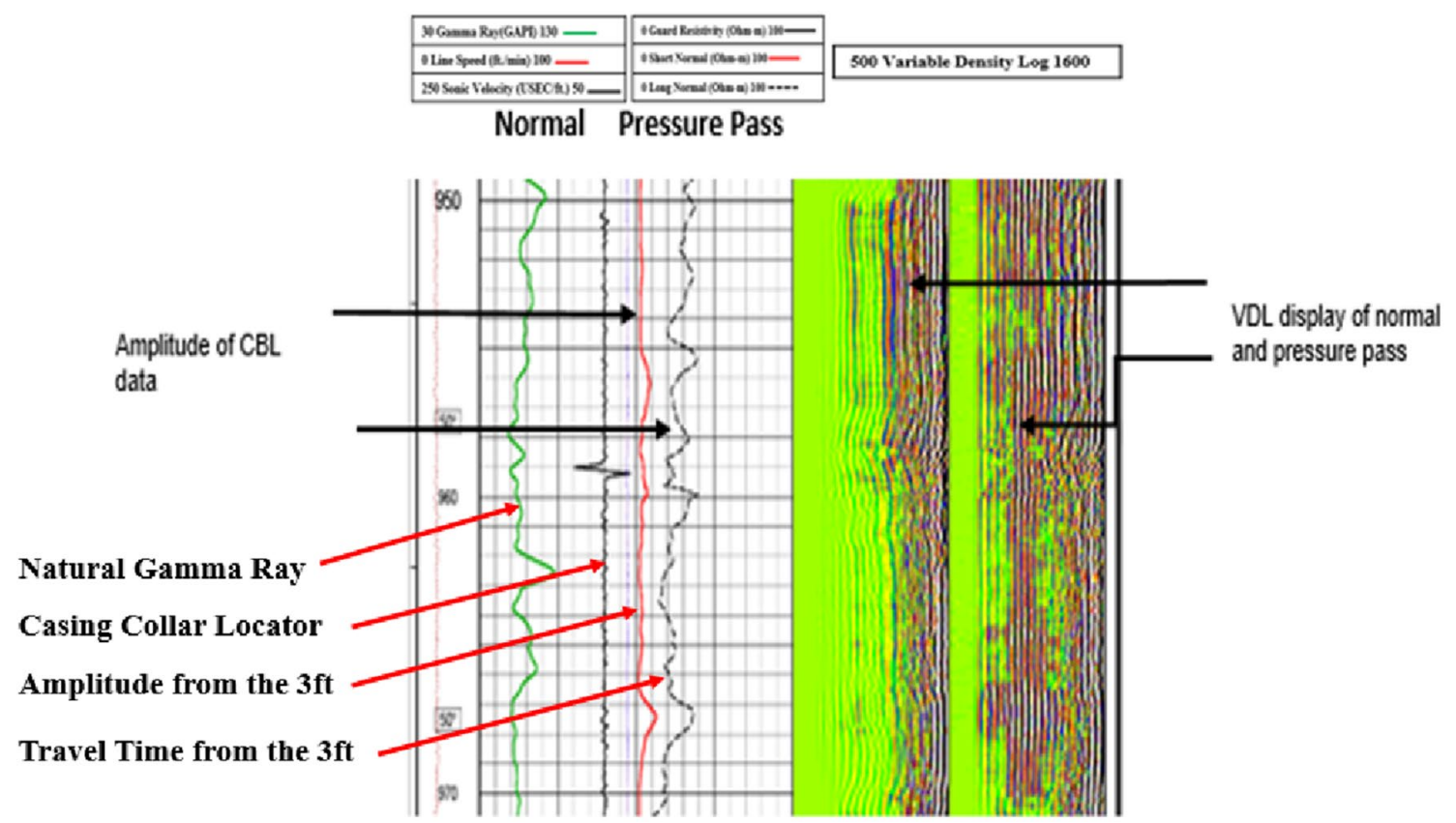

Fig. 5 CBL-VDL data with pressure pass

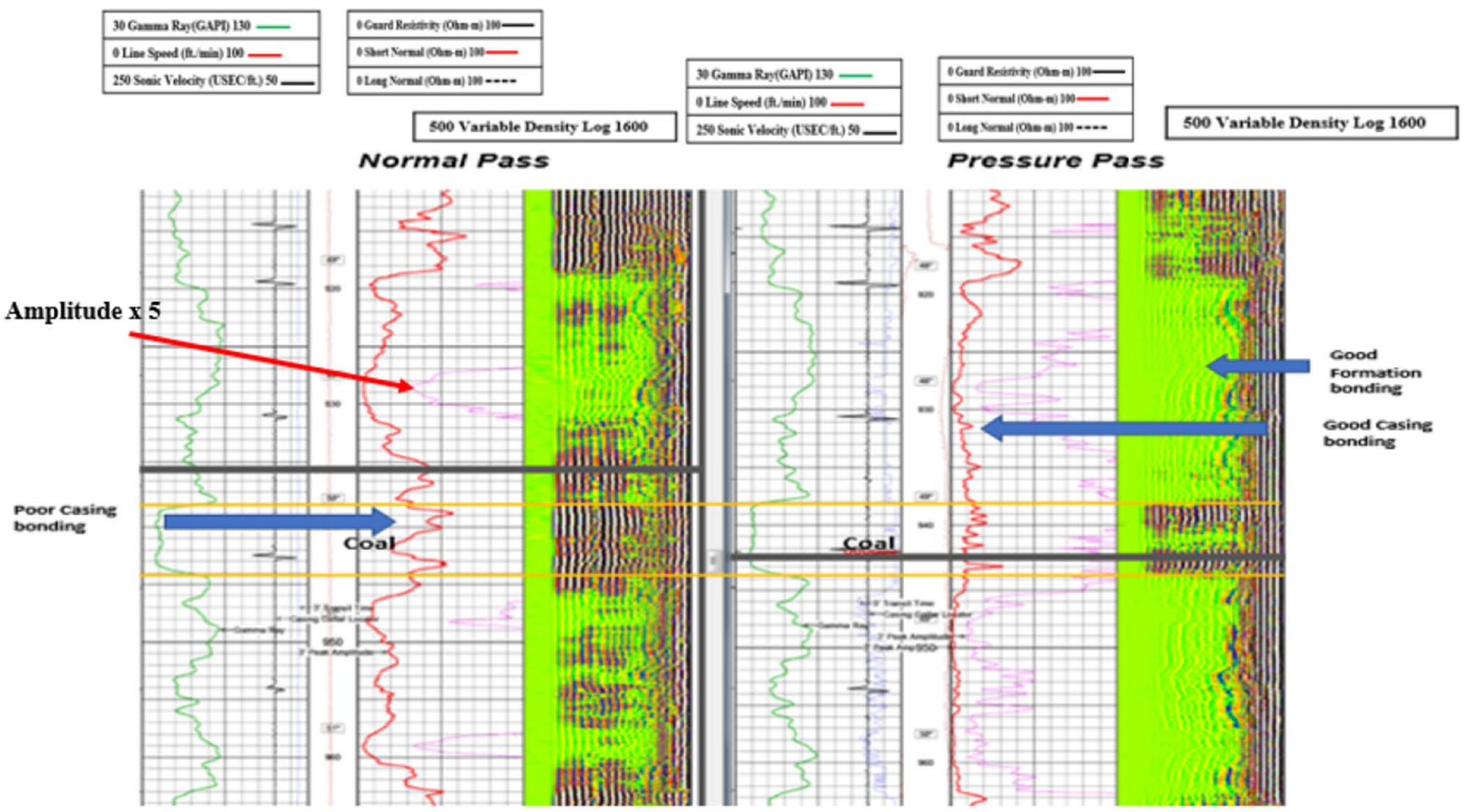

Fig. 6 Well A, logging response for normal and pressure pass at the depth 910-965 m

VDL data showed weak cement-formation bonding due to inadequate formation arrival (Fig. 7). A good cement-formation bonding was observed after the pressure pass at the same depth, i.e., 775-830 m (Fig. 7). The microannulus was observed at the depth varied from 775 to $830 \mathrm{~m}$ indicating poor cementing in normal pass. The pressure pass, as represented in Fig. 6, confirmed the presence of a microannulus. No microannulus was observed in the coal zone at a depth 


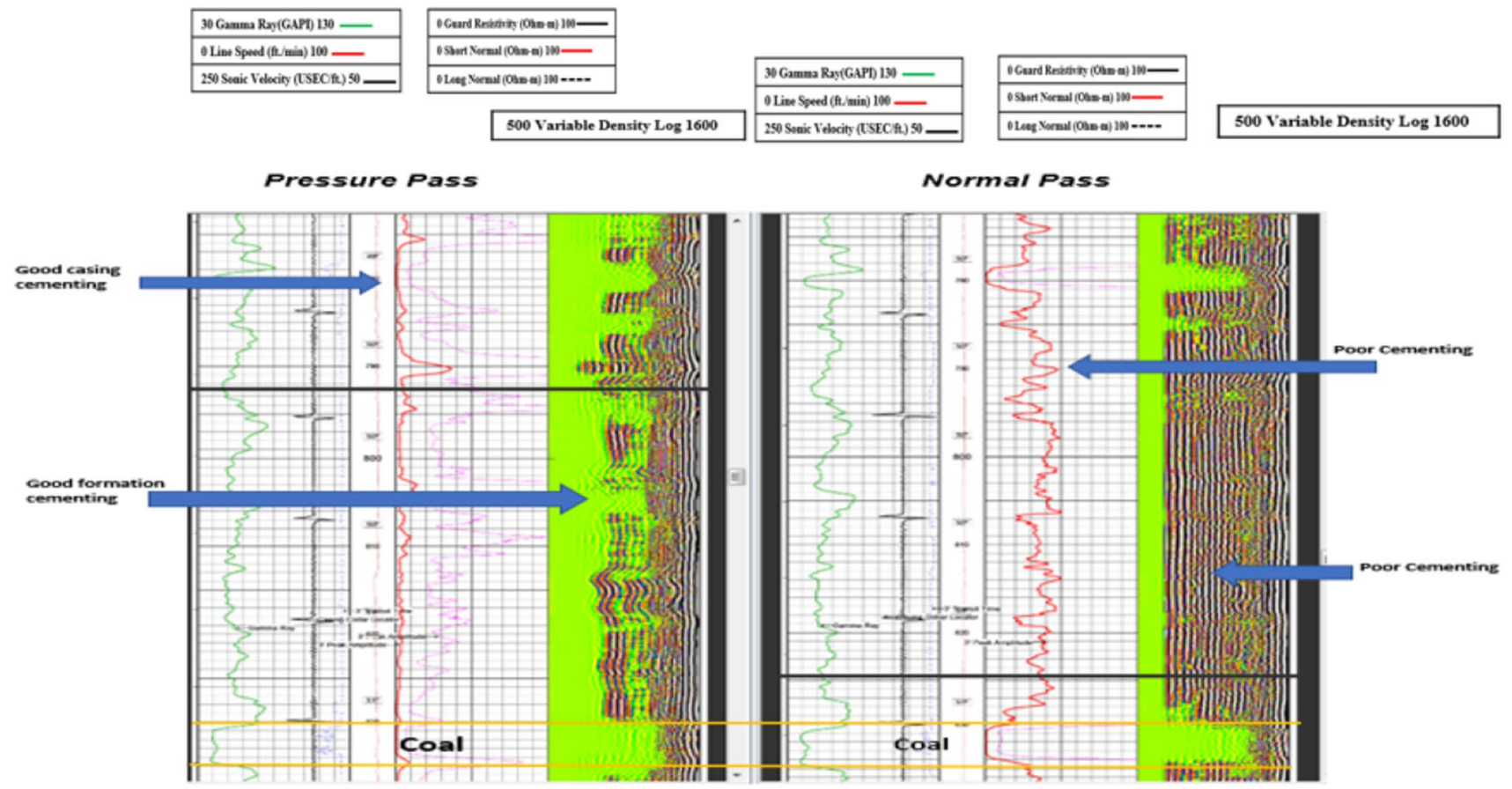

Fig. 7 Well B logging response for normal and pressure pass at $775-835 \mathrm{~m}$

of $830 \mathrm{~m}$, indicating a good cement-formation bond quality. The microannulus was not found in the coal zone in well B, as shown by the CBL-VDL data (Fig. 7). Thus, the decision was made to perforate the coal seam with good bond quality, as shown by CBL-VDL data. Thus, the gas production rate will not be affected due to the non-macroannulus and good cement-formation bond at the coal zone.

\section{Discussions}

The CBL-V log data in case study I for well A showed the microannulus's presence between the cement-formation bonding with an increase in depth from 910 to $965 \mathrm{~m}$ (Fig. 5) in normal pass. The microannulus was observed with a poor casing bond, particularly in the coal seam zone. This poor casing bond leads to leakage of the gas and hindrance in the continuity of gas flow as well as the integrity of the well. A pressure pass was carried out to overcome the cement casing and formation bonds and the problem of the microannulus that cause a disturbance in the integrity of the well. The pressure pass results indicated good casing and formation bonding above and below the coal seam zone, but the bonding was not satisfactory in the coal seam zone (Fig. 5). The microannulus in the coal seam zone was due to the fragile nature of the coal. The poor cement-casing-formation bond was due to the poor formation arrival and poor cementing in the well. The less effective pressure pass was also observed with the poor cementing in the well.
The well B in case study II was observed at the depth from 775 to $835 \mathrm{~m}$ (Fig. 6). The normal pass showed poor cement-casing-formation bond throughout the well except the coal seam zone. A good cement formation bond was due to the better cementing in well. The microannulus in the well was reduced by the application of the pressure pass (Fig. 6). The results after pressure pass indicated a good cement-casing-formation bond throughout the well. The results thus indicated the cementing as one of the important factors for the good cement-casing-formation bond in the well and satisfactory continuity of the gas flow as well as the integrity of the well.

\section{Lesson learn}

The CBL-VDL log was important for the observation of the microannulus in the well. The log data of normal and pressure pass indicated the variation in the microannulus between cement-casing-formation bonds. Thus, the CBL-V log plays an important role in maintaining the continuity of the gas flow and the integrity of the well.

\section{Conclusion}

Based on the investigations in this study the following conclusions were drawn. 
- Case study I indicated well A with poor cement-casingformation bond in coal seam zone in normal and pressure pass at the depth from 910 to $965 \mathrm{~m}$

- Case study II indicated well B with poor cement-casingformation bond in normal pass but good cement-casingformation bond in pressure pass in coal seam zone

- Hindrance in the gas flow and sand inflow was observed with the presence of microannulus in the cement-casingformation bonds

- The CBL-VDL data was found important to determine the presence of microannulus in the wellbore

- Cement Bond Logs like CBL/VDL plays an important role in observation of microannulus in the production well

Acknowledgement Herewith I would like to thank Essar Oil and Gas Exploration and Production Limited, Molandighi, Durgapur, West Bengal, India, for the permission to continue my research work. I would also take this opportunity to thank my mentor Mr. Tarun Gaur, Manager Geophysics, EOGEPL, for extending his help and cooperation during the research work.

Funding The fieldwork was carried out at Essar oil and gas exploration and production limited. The collected data were used for research and publication purposes. Therefore, there was no funding for this work.

Open Access This article is licensed under a Creative Commons Attribution 4.0 International License, which permits use, sharing, adaptation, distribution and reproduction in any medium or format, as long as you give appropriate credit to the original author(s) and the source, provide a link to the Creative Commons licence, and indicate if changes were made. The images or other third party material in this article are included in the article's Creative Commons licence, unless indicated otherwise in a credit line to the material. If material is not included in the article's Creative Commons licence and your intended use is not permitted by statutory regulation or exceeds the permitted use, you will need to obtain permission directly from the copyright holder. To view a copy of this licence, visit http://creativecommons.org/licenses/by/4.0/. and ultrasonic technologies in wells with microannulus between casing and cement sheath. In: SPE Annual Caspian Technical Conference and Exhibition. Society of Petroleum Engineers. pp 1-12, doi: https://doi.org/10.2118/172309-ms

Cai J et al (2016) Decreasing coalbed methane formation damage using microfoamed drilling fluid stabilized by silica nanoparticles. J Nanomater. https://doi.org/10.1155/2016/9037532

Chakrabortty R, Pal SC, Malik S, Das B (2018) Modeling and mapping of groundwater potentiality zones using AHP and GIS technique: a case study of Raniganj Block, Paschim Bardhaman, West Bengal. Model Earth Syst Environ 4(3):1085-1110. https://doi.org/ 10.1007/s40808-018-0471-8

Essar Exploration and Production, (2015) Unconventional Gas E\&P: Essar Approach. Peninsula Techno-park, Tower II, LBS Marg, Mumbai 400070, India, 26 -27th November

Jie $\mathrm{H}$ et al (2014) Log evaluation of a coalbed methane (CBM) reservoir: a case study in the southern Qinshui basin China. J Geophys Eng. https://doi.org/10.1088/1742-2132/11/1/015009

K. K. Kyi and A. G. J. Wang (2015) Issues with Cement Bond and Cement Evaluation Logs - Case Studies from Offshore Malaysia. December 2015, doi: https://doi.org/10.2523/iptc-18538-ms

Liu H (2017) Principles and applications of well logging. Springer, Berlin

Loizzoa M, Miersemannb U, Lamyc P, Garnier A (2013) Advanced cement integrity evaluation of an old well in the Rousse field. Energy Procedia 37:5710-5721

N Pal and MM Ahmed, (2006) Value addition using cement evaluation by ultrasonic imaging tool in upper Assam oil fields. In: 6th international conference and exposition on petroleum geophysics, Kolkata India, pp 554-558

R. Ashena, G. Thonhauser, C. Eng, and D. Dianati, (2014) Assessment of reliability of cement bond evaluation with some detection of different channels in the cement and cement bond logs the importance of reliable cement bond logs in preventing catastrophes cement bond $\log (\mathrm{CBL})$. pp 1-16

Thiercelin MJ, Dargaud B, Baret JF, Rodriquez WJ (1998) Cement design based on cement mechanical response. SPE Drill Complet. https://doi.org/10.2118/52890-PA

Wang H, Tao G, Shang X (2016) Understanding acoustic methods for cement bond logging. J Acoust Soc Am 139:2407-2416

Publisher's Note Springer Nature remains neutral with regard to jurisdictional claims in published maps and institutional affiliations.

\section{References}

A Timonin, P Kravets, and D Lungershausen (2014) Microannulus and cement evaluation: Effectiveness of cement evaluation using sonic 